\title{
Kinetic models for the oxy-fuel combustion of coal and coal/biomass blend chars obtained in $\mathrm{N}_{2}$ and $\mathrm{CO}_{2}$ atmospheres
}

\author{
M.V. Gil, J. Riaza, L. Álvarez, C. Pevida, J.J. Pis, F. Rubiera* \\ Instituto Nacional del Carbón, INCAR-CSIC, Apartado 73, 33080 Oviedo, Spain
}

\begin{abstract}
The thermal reactivity and kinetics of five coal chars, a biomass char, and two coal/biomass char blends in an oxy-fuel combustion atmosphere $\left(30 \% \mathrm{O}_{2}-70 \% \mathrm{CO}_{2}\right)$ were studied using the non-isothermal thermogravimetric method at three heating rates. Fuel chars were obtained by devolatilization in an entrained flow reactor at $1273 \mathrm{~K}$ under $\mathrm{N}_{2}$ and $\mathrm{CO}_{2}$ atmospheres. Three $n$ th-order representative gas-solid models - the volumetric model (VM), the grain model (GM) and the random pore model (RPM) were employed to describe the reactive behaviour of the chars. The RPM model was found to be the best for describing the reactivity of the high rank coal chars, while VM was the model that best described the reactivity of the bituminous coal chars, the biomass char and the coal-biomass blend char. The kinetic parameters of the chars obtained in $\mathrm{N}_{2}$ and $\mathrm{CO}_{2}$ in an oxy-fuel combustion atmosphere with $30 \%$ of oxygen were compared, but no relevant differences were observed. The behaviour of the blend of the bituminous coal (90\%wt.) and the biomass (10\%wt.) chars resembled that of the individual coal concealing the effect of the biomass. Likewise, no interaction was detected between the high rank coal and the biomass chars during oxy-fuel combustion of the blend.
\end{abstract}

\footnotetext{
* Corresponding author. Tel.: +34 985118 975; Fax: +34 985297662

E-mail address: frubiera@incar.csic.es (F. Rubiera)
} 
Keywords: Coal; Biomass; Non-isothermal TG; Oxy-fuel combustion; Kinetic models; Entrained flow reactor

\section{Introduction}

Whereas power generation from $\mathrm{CO}_{2}$-neutral renewable fuels is being promoted, coal utilization is expected to continue in the future, as the reserves of coal are abundant and its cost is relatively low [1]. However, the use of coal in power plants generates a large amount of $\mathrm{CO}_{2}$, which is the chief contributor to global climate change. One of the promising technologies being developed to facilitate carbon capture and storage (CCS) from fossil-fuel-fired power plants is the oxy-fuel combustion. The oxy-coal combustion together with carbon sequestration is a strategy that has received considerable attention as a viable, cost-effective technology for power production and that can be used as a retrofit on existing coal-fired power plants. This technology involves the combustion of pulverized coal in a mixture of oxygen and recycled flue gas (RFG), which consists mainly of $\mathrm{CO}_{2}$ and $\mathrm{H}_{2} \mathrm{O}$ [2]. In this process, the net volume of flue gas is reduced and a $\mathrm{CO}_{2}$ volume fraction in the flue gas of $95 \%$ or higher is provided, which after purification can be directly stored in a supercritical state by means of compression.

The oxy-coal combustion is expected to be different from the coal combustion under an $\mathrm{O}_{2} / \mathrm{N}_{2}$ atmosphere as the $\mathrm{CO}_{2}$ has higher specific molar heat capacity and varying radiation properties compared to those of $\mathrm{N}_{2}$. Previous research studies have focused on the fact that the use of $\mathrm{CO}_{2}$ instead of $\mathrm{N}_{2}$ may cause a reduction in the propagation speed, flame stability and gas temperature profile or lead to an increase in the unburned 
carbon content. Thus, Liu et al. [3] concluded that during the oxy-fuel combustion process, these problems can be overcome by increasing the oxygen concentration in the oxidizer (up to approximately $30 \%$ ) to match the combustion performance achieved in air. However, the reaction models and kinetics to describe coal combustion in $\mathrm{O}_{2} / \mathrm{CO}_{2}$ atmosphere have been scarcely studied. The knowledge of the effect of the $\mathrm{CO}_{2}$ atmosphere on the reactivity of coal is needed for evaluating the kinetic parameters required for computational fluid dynamics (CFD) calculations [4], which will be useful for designing and modelling oxy-fuel combustion at industrial scale. There are a few recent studies on the calculation of the kinetic parameters of the combustion of coal in an oxy-fuel atmosphere. Niu et al. [5,6] carried out the coal combustion in $\mathrm{O}_{2} / \mathrm{CO}_{2}$ mixtures on a thermogravimetric analyzer and calculated the kinetic parameters which describe the combustion process by linearization using the Coats-Redfern method. Wang et al. [7] compared the combustion of coals and chars in oxy-fuel atmosphere applying the non-isothermal thermogravimetric analysis, but these authors claimed that insufficient information exits on the effect of char preparation atmosphere on the char reactivity.

Thermogravimetric analysis (TGA) is a common technique used to investigate and compare thermal events and determine kinetic parameters during the combustion, pyrolysis and gasification of solid raw materials, such as coal, wood, etc. [8-14]. Moreover, quantitative methods can be applied to TGA curves to obtain kinetic parameters of the thermal events. Miura and Silveston [15] showed the validity of the temperature-programmed reaction (TPR) technique for the analysis of noncatalytic gassolid reactions. This technique appears to provide more kinetic information than what is obtainable from the same number of experiments performed at constant temperature. 
Kasaoka et al. [16] also stated that in an isothermal experiment, a tedious repetition of experimental runs is required to determine the kinetic parameters of the Arrhenius equation.

On the other hand, with the EU announcing that it intends to supply $20 \%$ of its overall energy needs from renewable sources by 2020, interest in biomass as a renewable source is growing [17]. This source of energy is considered carbon neutral because the carbon dioxide released during biomass utilization is recycled as an integral part of the carbon cycle. Co-combustion of biomass and coal has generated widespread interest because of the reduced emissions of gases such as $\mathrm{CO}_{2}, \mathrm{SO}_{2}$ and $\mathrm{NO}_{x}$ compared to those emitted by the combustion of coal [18]. The cofiring of biomass with coal is advantageous since biomass has higher volatile matter content and lower devolatilization temperature, which can aid the ignition and combustion characteristics of the blend [19]. Lai et al. [20] compared the combustion behaviour of lignocellulosic materials in $\mathrm{CO}_{2} / \mathrm{O}_{2}$ and $\mathrm{N}_{2} / \mathrm{O}_{2}$ atmospheres and calculated the kinetic parameters considering three parallel reactions during the combustion. A few studies have been published on the oxy-fuel combustion of coal and biomass blends [21-23], but reactivity and kinetic studies of biomass and coal/biomass blends under oxy-fuel combustion needs to be carried out.

The aim of the present work was to study the oxy-fuel combustion $\left(30 \% \mathrm{O}_{2}-70 \% \mathrm{CO}_{2}\right)$ reactivity and kinetic behaviour of five coal chars and a biomass char obtained under $100 \% \mathrm{~N}_{2}$ and $100 \% \mathrm{CO}_{2}$ atmospheres, as well as the coal/biomass char blends. For this purpose, the temperature-programmed reaction (TPR) technique at three different heating rates was used. Three mathematical models - the volumetric model (VM), the grain model (GM) and the random pore model (RPM) - were used to determine the 
kinetic parameters which best represent the oxy-fuel combustion characteristics of the coal char, biomass char and coal/biomass char blends under an oxygen-carbon dioxide atmosphere.

\section{Experimental}

\subsection{Fuel samples}

Five coals were used in this work: an anthracite (AC), a semi-anthracite (HVN) and three high-volatile bituminous coals (DAB, M6N and NZ). A type of biomass, torrefacted pine sawdust (TPIN), was also employed. The coal and biomass samples were ground, sieved and the resulting 75-150 $\mu \mathrm{m}$ size fraction was used for the devolatilization tests. The results of the proximate and ultimate analyses and high heating values of the coal and biomass samples are shown in Table 1.

The torrefaction of the biomass was carried out to improve its properties for pulverised systems [24]. To obtain the TPIN sample, a raw pine sawdust sample was ground and sieved to obtain a particle size fraction of $75-212 \mu \mathrm{m}$. Then, the torrefaction of this sample was performed using a vertical quartz reactor with a diameter of $20 \mathrm{~mm}$ and a length of $50 \mathrm{~mm}$, where $10-15 \mathrm{~g}$ of biomass was kept at a temperature of $513 \mathrm{~K}$ for $1 \mathrm{~h}$

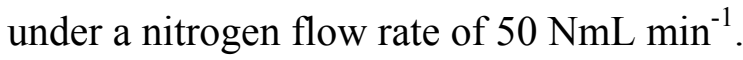

\subsection{Char preparation}

The chars were prepared by devolatilizing the raw fuels in an electrically heated entrained flow reactor (40 $\mathrm{mm}$ internal diameter, $1400 \mathrm{~mm}$ length) in streams of $100 \%$ $\mathrm{N}_{2}$ and $100 \% \mathrm{CO}_{2}\left(4.79 \mathrm{NL} \mathrm{min}^{-1}\right)$. The experimental device has been described elsewere [25,26]. The devolatilization experiments were carried out at a reactor 
temperature of $1273 \mathrm{~K}$ and a particle residence time of $2.5 \mathrm{~s}$. After the experiments, the chars were cooled down under a flow of nitrogen to room temperature and a watercooled collecting probe was inserted into the reaction chamber from below to collect the char samples. The obtained coal and biomass char samples were used for the oxy-fuel combustion reactivity experiments. Moreover, two blends, AC+TPIN and DAB+TPIN, composed of $10 \mathrm{wt} \%$ of biomass char TPIN-CO2 and $90 \mathrm{wt} \%$ of coal char AC-CO2 or DAB-CO2, respectively, were prepared. The components of the mixtures were blended in the adequate proportions and manually homogenized.

\subsection{Oxy-fuel combustion reactivity tests of the chars}

The reactivity tests were conducted in a thermobalance (Setaram TAG24) at atmospheric pressure. Approximately $5 \mathrm{mg}$ of sample was placed in a crucible of $2 \mathrm{~mm}$ height with a circular base of $5 \mathrm{~mm}$ diameter. A small amount of sample and slow heating rates were used to avoid heat transfer limitations and to minimize mass transfer effects. A thermocouple was located close to the platinum basket to monitor the temperature and to close the oven control loop. In this work, all the experiments were performed under non-isothermal conditions from room temperature to $1273 \mathrm{~K}$ at three different heating rates: 2,3 and $5 \mathrm{~K} \mathrm{~min}^{-1}$. For the NZ samples, the heating rates used were: 1,2 and $3 \mathrm{~K} \mathrm{~min}^{-1}$. The total flow rate of the gas introduced into the thermobalance during the oxy-fuel combustion experiments was $50 \mathrm{NmL} \mathrm{min}^{-1}$, the gas consisting of $30 \% \mathrm{O}_{2}$ and $70 \% \mathrm{CO}_{2}$. The char conversion, $X$, and the reaction rate, $\mathrm{d} X / \mathrm{d} t$, were calculated. The TG reactivity tests were firstly performed for the coal and biomass chars separately, and then for the coal/biomass char blends. 


\section{Kinetic models}

A general kinetic expression for the overall reaction rate in gas-solid reactions is written as follows [27]:

$\mathrm{d} X / \mathrm{d} t=k\left(P_{\mathrm{g}}, T\right) f(X)$

where $k$ is the apparent combustion reaction rate, which includes the effect of temperature $(T)$ and the effect of the reactive gas partial pressure $\left(P_{g}\right)$, and $f(X)$ describes the changes in the physical or chemical properties of the sample during reaction. $X$ represents the loss in mass fraction or mass conversion ratio, which can be calculated by the following relationship:

$X=\left(m_{0}-m_{t}\right) /\left(m_{0}-m_{f}\right)$

where $m_{0}$ is the initial mass of the char sample, $m_{t}$ the mass of the char sample at time $t$ and $m_{f}$ the final mass of the char sample.

Assuming that the partial pressure of the reactive gas remains constant during the process, the apparent combustion reaction rate will be dependent on the temperature and can be expressed using the Arrhenius equation, as follows:

$k=k_{0} e^{-E / R T}$

where $k_{0}$ and $E$ are the pre-exponential factor and activation energy, respectively.

In this work, three $n$ th-order models were applied to describe the reactivity of the chars studied: the volumetric model (VM), the grain model (GM) and the random pore model (RPM). These models give different formulations of the term $f(X)$, with $X$ representing the degree of char conversion on a dry ash-free basis.

The VM assumes a homogeneous reaction throughout the particle and a linearly decreasing reaction surface area with conversion [28]. The overall reaction rate is expressed by: 
$\mathrm{d} X / \mathrm{d} t=k_{\mathrm{VM}}(1-X)$

The GM or shrinking core model, proposed by Szekely and Evans [29], assumes that a porous particle consists of an assembly of uniform nonporous grains and that the reaction takes place on the surface of these grains. The space between the grains constitutes the porous network. The shrinking core behaviour applies to each of these grains during the reaction. In the regime of chemical kinetic control and, assuming the grains have a spherical shape, the overall reaction rate can be expressed as:

$\mathrm{d} X / \mathrm{d} t=k_{\mathrm{GM}}(1-X)^{2 / 3}$

This model predicts a monotonically decreasing reaction rate and surface area because the surface area of each grain is receding during the reaction.

The RPM model considers the overlapping of pore surfaces, which reduces the area available for reaction [30]. The basic equation for this model is:

$\mathrm{d} X / \mathrm{d} t=k_{\mathrm{RPM}}(1-X)[1-\psi \ln (1-X)]^{1 / 2}$

This model is able to predict a maximum value of reactivity as the reaction proceeds, as it considers the competing effects of pore growth during the initial stages of combustion and the destruction of the pores due to the coalescence of neighbouring pores during the reaction. The RPM model employs two parameters, the apparent combustion reaction rate constant, $k_{\mathrm{RPM}}$, and $\psi$, which is related to the pore structure of the unreacted sample, although Miura and Silveston [15] suggested that the $\psi$ parameter should be considered as an adjustable parameter.

The non-isothermal thermogravimetric method or temperature-programmed reaction (TPR) technique involves heating the samples at a constant rate, $a$. The temperature, $T$, is related to time, $t$, by:

$T=T_{0}+a t$ 
where $T_{0}$ is the temperature at which heating is started, which can be set equal to 0 provided that $T_{0}$ is low enough for the reaction rate to be practically zero when heating is initiated.

By means of Equation (7), Equation (4) can be integrated to give:

$$
X=1-\exp \left(-\frac{k_{0} E}{a R} p(u)\right)
$$

where

$$
p(u)=\frac{e^{-u}}{u}-\int_{X}^{\infty} \frac{e^{-u}}{u} d u
$$

$u=E / R T$

From the literature, several proposed approximations for $p(u)$ can be found. In this study the one employed has been [15,31-32]:

$p(u)=e^{-u} / u^{2}$

This approximation is valid for $u>10$, which is fulfilled by these fuels when burned in the studied oxy-fuel atmosphere. Equation (8) can then be written as:

$$
X=1-\exp \left[-\frac{R T^{2}}{a E} k_{0} e^{\frac{-E}{R T}}\right]
$$

Similarly, Equations (5) and (6) can be integrated with the above approximation, to give Equations (13) and (14) respectively:

$$
\begin{aligned}
& X=1-\left[1-\frac{R T^{2}}{3 a E} k_{0} e^{\frac{-E}{R T}}\right]^{3} \\
& X=1-\exp \left[-\frac{R T^{2}}{a E} k_{0} e^{\frac{-E}{R T}}\left(1+\frac{\psi}{4}\left(\frac{R T^{2}}{a E}\right) k_{0} e^{\frac{-E}{R T}}\right)\right]
\end{aligned}
$$

Equations (12)-(14) can be utilized to determine $k_{0}$ and $E$ values from $X$ experimental data sets by employing nonlinear least-squares fitting methods. According to Miura and 
Silveston [15], the determination of the kinetic parameters from a single TPR run may lead to unreliable rate parameters and, furthermore, the fitting of data by a model may not validate the model if just one TPR run is used. These authors claimed that at least three TPR runs at different heating rates are required to estimate reliable parameters and accurate activation energies.

In this study the kinetic parameters were determined from three TPR runs, each one performed at a different heating rate. The nonlinear least-squares method was employed to fit the experimental data of $1-X$ vs. temperature, $T$, to the three models by means of Equations (12)-(14), and to estimate the $k_{0}$ and $E$ values which minimize the objective function, $\mathrm{OF}$ :

$\mathrm{OF}=\sum_{i=1, \mathrm{~N}}\left[(1-X)_{\exp , i}-(1-X)_{\mathrm{calc}, i}\right]^{2}$

where $(1-X)_{\exp , i}$ is the experimental point corresponding to the $i^{\text {th }}$ temperature, $T_{i}$, (1$X)_{\text {calc, } i}$ is the value calculated at $T_{i}$, and $N$ is the number of data points.

According to Várhegyi [33], the method of least squares can work better in nonisothermal kinetics than other methods requiring simpler computer programming or less computational time, since this technique aims directly at the description of the experimental data in a wide range of experimental conditions.

To assess the quality of the fit and verify the capacity of the kinetic models to describe the degree of char conversion, $X$ (or 1-X), the deviation (DEV) between the experimental and calculated curves was obtained using the following expression:

$\operatorname{DEV}(1-X)(\%)=100\left[\Sigma_{i=1, N}\left((1-X)_{\exp , i}-(1-X)_{\mathrm{calc}_{,},{ }^{2} / \mathrm{N}}\right]^{1 / 2} / \max (1-X)_{\exp }\right.$ where $(1-X)_{\exp , i}$ and $(1-X)_{\text {calc }, i}$ represent the experimental and calculated data of $1-X, N$ is the number of data points, and $\max (1-X)_{\exp }$ is the highest absolute value of the experimental curve. The best fitting kinetic parameters and model were chosen from the 
highest $R^{2}$ value obtained from the results which proved to be statistically significant, together with the lowest value of DEV $(1-X)$.

\section{Results and discussion}

\subsection{Kinetic parameters}

Table 2 shows the kinetic parameters $\left(E, k_{0}\right.$ and $\left.\psi\right)$ determined from the data obtained at three heating rates $\left(1,2\right.$ and $3 \mathrm{~K} \mathrm{~min}^{-1}$ for the $\mathrm{NZ}$ coal char and 2,3 and $5 \mathrm{~K} \mathrm{~min}^{-1}$ for the rest of samples) together with the coefficients of determination, $R^{2}$, for each model and sample. $R^{2}$ shows the variation in the dependent variable, $1-X$, which is explained by the model. Table 2 also presents the statistically significant model fittings.

The RPM model fits the experimental data better than the other two models for coal chars AC-N2 $\left(R^{2}=0.999\right), \mathrm{AC}-\mathrm{CO} 2\left(R^{2}=0.999\right), \mathrm{HVN}-\mathrm{N} 2\left(R^{2}=0.998\right)$ and HVN-CO2 $\left(R^{2}=0.998\right)$, since it displayed a significant fit and presented the highest $R^{2}$ value (Table 2). In the case of the DAB, M6N and NZ char samples, as well as the DAB+TPIN blend, the $\psi$ value obtained from the RPM model is a meaningless negative value, which indicates that the best fit to the experimental data is obtained with a $\psi$ value of zero. For the TPIN samples, the $\psi$ value obtained from the RPM model is close to zero and the fits were not significant. When the $\psi$ value is close to zero, the RPM model predicts a nearly constant decrease in reactivity with conversion, as does the VM model. Therefore, it can be concluded that the model which best describes the reactivity of the DAB-N2 $\left(R^{2}=0.998\right), \mathrm{DAB}-\mathrm{CO} 2\left(R^{2}=0.998\right), \mathrm{M} 6 \mathrm{~N}-\mathrm{N} 2\left(R^{2}=0.995\right), \mathrm{M} 6 \mathrm{~N}-\mathrm{CO} 2$ $\left(R^{2}=0.996\right), \mathrm{NZ}-\mathrm{N} 2\left(R^{2}=0.998\right), \mathrm{NZ}-\mathrm{CO} 2\left(R^{2}=0.996\right), \mathrm{TPIN}-\mathrm{N} 2\left(R^{2}=0.998\right)$ and TPIN-CO2 $\left(R^{2}=0.996\right)$ char samples, as well as the DAB+TPIN $\left(R^{2}=0.999\right)$ blend, was the VM model (Table 2). On the other hand, the reactivity of the AC+TPIN blend 
has not been satisfactorily described by none of the considered models, since the oxyfuel combustion process took place in two stages and it was not then possible to obtain a simple set of kinetic parameters for this sample.

The RPM model predicts a maximum in reaction rate as the reaction proceeds, as pore overlapping is considered. Pore shape is assumed cylindrical and supposed to grow radially while reaction proceeds, instead of keeping initial volume. Initially, the cylinders growth causes an increase in total reaction surface, which means higher reaction rate. Finally, reaction progress brings about a neighbouring pore intersection. Due to pore overlapping, the reaction surface area is lower and, consequently, the reaction rate decreases [34]. Conversely, the VM and GM models cannot describe a maximum in reaction rate but predict a constant decrease in the reaction rate with conversion. Therefore, from the results of the model fits it can be deduced that, in the case of the high rank coals used in this work, $\mathrm{AC}$ and $\mathrm{HVN}$, the char reaction rate presents a maximum value during combustion. However, for the bituminous coals (DAB, M6N and NZ), the biomass sample (TPIN) and the coal/biomass blend (DAB+TPIN) the char reaction rate decreases linearly during the whole oxy-fuel combustion process under the conditions of the present study.

Figs. 1 and 2 show, for the three heating rates, the experimental $1-X$ data and the $1-X$ curves calculated (Equations (12)-(14)) using the parameters obtained from the data at the three heating rates for the meaningful and statistically significant models (Table 2). As example, the curves for the AC, $\mathrm{HVN}$ and DAB char samples obtained both in $\mathrm{N}_{2}$ and $\mathrm{CO}_{2}$ are shown in Fig. 1 and the curves for the biomass char, TPIN, and the blends, $\mathrm{AC}+\mathrm{TPIN}$ and DAB+TPIN, are shown in Fig. 2. To quantify the errors produced by the kinetic models in predicting the values of conversion, the deviation (DEV) between the 
experimental and calculated $1-X$ curves was obtained using the Equation (16). The results obtained from the significant models for all the char samples and the blend are summarised in Table 3. In accordance with the previous results (Table 2), the lowest deviation from the calculated values of the conversion rates was obtained using the RPM model for all the AC and HVN char samples and the VM model for all the DAB, M6N, NZ, TPIN and DAB+TPIN samples (Table 3). Saravanan et al. [4] and Gil et al. [35] have also studied the reactivity of coal chars during oxy-fuel combustion using the random pore model. Gil et al. [35] found that RPM model was the best for describing the reactivity of coal chars.

Table 4 summarizes the activation energy values obtained for the char samples used in the present study, together with data from previous works on oxy-fuel combustion. In the present work, using the models of best fit, the activation energy for the coal chars under $30 \% \mathrm{O}_{2}-70 \% \mathrm{CO}_{2}$ atmosphere was $116-171 \mathrm{~kJ} \mathrm{~mol}^{-1}$ (Table 2). In a previous study, Gil et al. [35] had calculated activation energy values for coal chars under oxy-fuel atmosphere with $30 \% \mathrm{O}_{2}$ of $117-127 \mathrm{~kJ} \mathrm{~mol}^{-1}$. Niu et al. [5] obtained activation energy values for pulverized coals in an oxy-fuel atmosphere $\left(20 \% \mathrm{O}_{2}\right)$ that ranged between 109 and $248 \mathrm{~kJ} \mathrm{~mol}^{-1}$. Similarly, Liu [36] achieved activation energy values for coal chars in an oxy-fuel atmosphere $\left(10 \% \mathrm{O}_{2}\right)$ which ranged between 115 and $147 \mathrm{~kJ} \mathrm{~mol}^{-1}$. On the other hand, the activation energy for the TPIN biomass char under $30 \% \mathrm{O}_{2}$ $70 \% \mathrm{CO}_{2}$ atmosphere was $118-129 \mathrm{~kJ} \mathrm{~mol}^{-1}$ (Table 2). In the case of the DAB+TPIN char blend, a value of the activation energy of $136 \mathrm{~kJ} \mathrm{~mol}^{-1}$ was obtained, which is an intermediate value between those of the individual components of the blend.

Table 2 shows that the activation energy values and pre-exponential factors for the two devolatilization atmospheres are very similar. From these data, it can be concluded that 
no differences in the kinetic parameters of oxy-fuel combustion under $30 \% \mathrm{O}_{2}-70 \% \mathrm{CO}_{2}$ atmosphere are produced by using $100 \% \mathrm{~N}_{2}$ and $100 \% \mathrm{CO}_{2}$ devolatilization atmospheres. Wang et al. [7] studied the devolatilization of coal samples in $100 \% \mathrm{~N}_{2}$ and $100 \% \mathrm{CO}_{2}$ by means of TGA and found that the TG and DTG curves in both atmospheres were almost superposing in the low temperature zone (up to $\sim 1073 \mathrm{~K}$ ), concluding that the pyrolysis reactivity is highly similar in $\mathrm{N}_{2}$ and $\mathrm{CO}_{2}$. At higher temperatures, however, in $\mathrm{CO}_{2}$ atmosphere char- $\mathrm{CO}_{2}$ gasification was observed, which is also in accordance with the results obtained by Rathnam et al. [37]. At the temperature used in the present study for obtaining the chars $(1273 \mathrm{~K})$, gasification process could therefore occur at some extent, which would affect the char characteristics. The additional char- $\mathrm{CO}_{2}$ reaction could then increase the reactivity of the coal char obtained under $\mathrm{CO}_{2}$ atmosphere. Nevertheless, the endothermic effect of char- $\mathrm{CO}_{2}$ reaction could also play a negative role in the enhancement of the reactivity through reducing the coal particle temperature. Wang et al. [7] pointed out the necessity of studies to clarify the circumstances in which those opposite effects will preponderate the other. These authors concluded that char reactivity (in $21 \% \mathrm{O}_{2} / 79 \% \mathrm{CO}_{2}$ ) prepared in $\mathrm{CO}_{2}$ is almost equivalent to that prepared in $\mathrm{N}_{2}$ in a study where coal chars were obtained at low temperature $(\sim 1073 \mathrm{~K})$ in a tubular furnace. Borrego et al. [38] studied the characteristics of the chars from various biomass materials generated at a high heating rate in a drop tube furnace (DTF) under $\mathrm{N}_{2}$ and $\mathrm{CO}_{2}$ atmospheres and they found that similar morphology, optical texture and specific surface area were shown by the biomass chars generated under both atmospheres. The reaction rate of a char under an oxygen atmosphere is usually very high and in the present study the reactivity was measured in a high oxygen content $(30 \%)$ atmosphere, which may have concealed possible differences in reactivity between both chars and 
may explain why no differences were observed between the chars obtained under $\mathrm{N}_{2}$ or $\mathrm{CO}_{2}$. Várhegyi et al. [39] studied the coal char kinetics in $\mathrm{O}_{2} / \mathrm{Ar}$ and $\mathrm{O}_{2} / \mathrm{CO}_{2}$ atmospheres by non-isothermal thermogravimetry and concluded that the char reaction rate was proportional to the $\mathrm{O}_{2}$ concentration of the ambient gas and was not influenced by the presence of high amounts of $\mathrm{CO}_{2}$ since char- $\mathrm{CO}_{2}$ reactions have much lower rates than char oxidation. Niu et al. [6] confirmed that for $\mathrm{O}_{2}$ concentrations of $30-40 \%$ in oxy-fuel atmospheres, the reaction process is mainly dominated by the diffusion of the $\mathrm{O}_{2}$ to the surface of the solid coal and the effect of the carrier gas is not very important.

The relative reactivity of $\mathrm{O}_{2}$ with coal is much greater than $\mathrm{CO}_{2}$ with coal, which suggests that the char oxidation in the present work was predominantly due to oxygen and a possible gasification reaction due to $\mathrm{CO}_{2}$ during the reactivity experiments would have not existed under these conditions. It was also noted by Saravanan et al. [4] in their study about the reactivity of coal chars during oxy-fuel combustion under different concentrations of $\mathrm{CO}_{2}$, who pointed out that the effect of $\mathrm{CO}_{2}$ concentration on the char oxidation rate in the presence of oxygen might be only due to the bulk resistance offered by $\mathrm{CO}_{2}$ during the char-oxygen reaction, although this fact would require more additional studies.

\subsection{Comparison of isothermal and non-isothermal reactivity tests}

In a previous study [35], a kinetic analysis of the oxy-fuel combustion of the HVN-N2 and HVN-CO2 char samples had been carried out by the authors at constant temperature. The results obtained using the TPR technique were then compared with those obtained from experiments performed at constant temperature. From the 
isothermal oxy-fuel combustion experiments, it was concluded that the best model for describing the behaviour of both HVN samples was RPM and the parameters estimated using this model by both techniques were therefore compared. Following the indications from Miura and Silveston [15], the values of $k_{0} e^{-E / R T}$ were calculated using the kinetic parameters in Table 2. They were plotted on an Arrhenius diagram (Fig. 3) and compared with those obtained in the isothermal experiments [34]. A good agreement can be observed between the $k_{0} e^{-E / R T}$ values estimated by both methods, indicating that the TPR technique provides reliable kinetics parameters when data from the three heating rates are used.

\subsection{Interactions between the components of the coal/biomass blends}

Fig. 4 shows the experimental $\mathrm{d} X / \mathrm{d} t$ curves for the coal/biomass blends (AC+TPIN and DAB+TPIN) under the oxy-fuel combustion atmosphere studied, together with the theoretical reaction rate curves calculated according to the additive rule from those of the individual components. The $\mathrm{d} X / \mathrm{d} t$ curves for the individual components of the blends were also included. The theoretical and experimental $\mathrm{d} X / \mathrm{d} t$ curves of the coal/biomass blends were compared to find out whether the components of the blends interacted during the oxy-fuel combustion process. As mentioned above, the theoretical $\mathrm{d} X / \mathrm{d} t$ curves of the blends were calculated according to the additive rule of blends, i.e.:

$(\mathrm{d} X / \mathrm{d} t)_{\text {blend }}=x_{1}(\mathrm{~d} X / \mathrm{d} t)_{\text {coal }}+x_{2}(\mathrm{~d} X / \mathrm{d} t)_{\text {biomass }}$

where $(\mathrm{d} X / \mathrm{d} t)_{\text {coal }}$ and $(\mathrm{d} X / \mathrm{d} t)_{\text {biomass }}$ are the reaction rate of the individual fuels, and $x_{1}$ and $x_{2}$ are the proportions of coal and biomass in the blend, respectively.

Fig. 4a shows that when the AC high rank coal and the TPIN biomass are co-combusted under oxy-fuel atmosphere, two independent peaks are observed in the DTG curves of 
the blend. Furthermore, no significant deviations are appreciated between the experimental and theoretical $\mathrm{d} X / \mathrm{d} t$ curves in the case of the AC+TPIN char blend at the three heating rates. This suggests that no significant interactions occur during char oxyfuel combustion with $30 \%$ of oxygen, reflecting the additive behaviour of blend components during the combustion process. This means that it should be possible to predict the experimental reactivity curve of the blend, on the basis of the experimental reactivity curves of each individual component and their percentages in the blend. The absence of synergetic effects during the char oxy-fuel combustion process, indicates that the oxy-fuel combustion reactions of the coal char did not seem to be influenced by the presence of $10 \mathrm{wt} \%$ of biomass char. Each component of the mixture behaved independently and did not interact with the other material.

When the experimental and theoretical $\mathrm{d} X / \mathrm{d} t$ curves for the DAB+TPIN blend are compared (Fig. $4 \mathrm{~b}$ ), it can be seen that $\mathrm{d} X / \mathrm{d} t$ curve of the blend closely resembled that of the coal char sample. This indicates that the addition of the TPIN biomass char to the DAB coal char, when added in a proportion of $10 \%$, has very little effect on the behaviour of the individual coal char.

\section{Conclusions}

The chars from five coals (AC, HVN, DAB, M6N and NZ) and a torrefacted biomass (TPIN) obtained in $\mathrm{N}_{2}$ or $\mathrm{CO}_{2}$ atmospheres, as well as two coal/biomass blends $(\mathrm{AC}+\mathrm{TPIN}$ and DAB+TPIN), were subjected to oxy-fuel combustion in a thermobalance to study their thermal reactivity. The temperature-programmed reaction technique employed in the analysis of noncatalytic gas-solid reactions was applied at three heating rates to estimate the kinetic parameters which best described the reactive 
behaviour of the chars during oxy-fuel combustion. The best model for describing the char oxy-fuel combustion of the AC and HVN high rank coals was found to be the RPM model, whereas the VM model better described the char reactivity of the DAB, M6N and NZ bituminous coals, the TPIN biomass and the DAB+TPIN blend under oxy-fuel conditions. The kinetic parameters showed that no differences in reactivity under a typical oxy-fuel combustion atmosphere $\left(30 \% \mathrm{O}_{2}-70 \% \mathrm{CO}_{2}\right)$ exist between chars obtained under $\mathrm{CO}_{2}$ and $\mathrm{N}_{2}$. No significant interactions were detected between the components of the coals-biomass blends chars $(90-10 \mathrm{wt} \%)$ with $30 \%$ of oxygen.

\section{Acknowledgements}

This work was carried out with financial support from the Spanish MICINN (Project PS-120000-2005-2) co-financed by the European Regional Development Fund (ERDF). M.V.G. and L.A. acknowledge funding from the CSIC JAE-Pre and CSIC JAE-Doc programs, respectively, co-financed by the European Social Fund. J.R. acknowledges funding from the Government of the Principado de Asturias (Severo Ochoa program).

\section{References}

[1] Deutch J, Moniz J. The Future of Coal: Options for a Carbon-Constrained World. Massachusetts Institute of Technology Interdisciplinary Study; 2007.

[2] $\mathrm{Hu} Y$, Yan J. Characterization of flue gas in oxy-coal combustion processes for $\mathrm{CO}_{2}$ capture. Appl Energy 2012;90:113-121.

[3] Liu H, Zailani R, Gibbs BM. Comparisons of pulverized coal combustion in air and in mixtures of $\mathrm{O}_{2} / \mathrm{CO}_{2}$. Fuel 2005;84:833-40.

[4] Saravanan V, Shivakumar R, Jayanti S, Ramakrishna, Seetharamu S. Evaluation of the effect of the concentration of $\mathrm{CO}_{2}$ on the overall reactivity of drop tube furnace derived Indian sub-bituminous coal chars during $\mathrm{CO}_{2} / \mathrm{O}_{2}$ combustion. Ind Eng Chem Res 2011;50:12865-71.

[5] Niu SL, Lu CM, Han KH, Zhao JL. Thermogravimetric analysis of combustion characteristics and kinetics parameters of pulverized coals in oxy-fuel atmosphere. J Therm Anal Calorim 2009;98:267-74. 
[6] Niu SL, Han KH, Lu CM. Characteristic of coal combustion in oxygen/carbon dioxide atmosphere and nitric oxide release during this process. Energy Conv Manag 2011;52:532-7.

[7] Wang C, Zhang X, Liu Y, Che D. Pyrolysis and combustion characteristics of coals in oxyfuel combustion. Appl Energy 2012; doi:10.1016/j.apenergy.2012.02.011.

[8] Lai ZY, Ma XQ, Tang YT, Lin H. A study on municipal solid waste (MSW) combustion in $\mathrm{N}_{2} / \mathrm{O}_{2}$ and $\mathrm{CO}_{2} / \mathrm{O}_{2}$ atmosphere from the perspective of TGA. Energy 2011;36:819-24.

[9] Fermoso J, Arias B, Pevida C, Plaza MG, Rubiera F, Pis JJ. Kinetic models comparison for steam gasification of different nature fuel chars. J Therm Anal Calorim 2008;91:779-86.

[10] Skodras G, Grammelis P, Basinas P. Pyrolysis and combustion behaviour of coalMBM blends. Bioresource Technol 2007;98:1-8.

[11] Wang C, Wang F, Yang Q, Liang R. Thermogravimetric studies of the behavior of wheat straw with added coal during combustion. Biomass Bioenerg 2009;33:50-6.

[12] Arenillas A, Rubiera F, Pis JJ, Cuest MJ, Iglesias MJ, Jiménez A, Suárez-Ruiz I. Thermal behaviour during the pyrolysis of low rank perhydrous coals. J Anal Appl Pyrol 2003;68-69:371-85.

[13] Yu YH, Kim SD, Lee JM, Lee KH. Kinetic studies of dehydration, pyrolysis and combustion of paper sludge. Energy 2002;27:457-69.

[14] Park SW, Jang CH. Effects of pyrolysis temperature on changes in fuel characteristics of biomass char. Energy 2012;39:187-95.

[15] Miura K, Silveston PL. Analysis of Gas-Solid Reactions by Use of a TemperatureProgrammed Reaction Technique. Energy Fuels 1989;3:243-9.

[16] Kasaoka S, Sakata Y, Shimada M, Matsutomi T. A new kinetic model for temperature programed thermogravimetry and its applications to the gasification of coal chars with steam and carbon dioxide. J Chem Eng Jpn 1985;18:426-32.

[17] European Commission Directive 2009/28/EC. Official Journal of the European Union L 140/16-162; 2009.

[18] Kazanc F, Khatami R, Crnkovic PM, Levendis YA. Emissions of $\mathrm{NO}_{x}$ and $\mathrm{SO}_{2}$ from coals of various ranks, bagasse, and coal-bagasse blends burning in $\mathrm{O}_{2} / \mathrm{N}_{2}$ and $\mathrm{O}_{2} / \mathrm{CO}_{2}$ environments. Energy Fuels 2011;25:2850-61.

[19] Sami M, Annamalai K, Wooldridge M. Co-firing of coal and biomass fuel blends. Progr Energy Combust Sci 2001;27:171-214.

[20] Lai ZY, Ma XQ, Tang YT, Lin H, Chen Y. Thermogravimentric analyses of combustion of lignocellulosic materials in $\mathrm{N}_{2} / \mathrm{O}_{2}$ and $\mathrm{CO}_{2} / \mathrm{O}_{2}$ atmospheres. Bioresource Technol 2012;107:444-50.

[21] Arias B, Pevida C, Rubiera F, Pis JJ. Effect of biomass blending on coal ignition and burnout during oxy-fuel combustion. Fuel 2008;87:2753-9.

[22] Gil MV, Riaza J, Álvarez L, Pevida C, Pis JJ, Rubiera F. A study of oxy-coal combustion with steam addition and biomass blending by thermogravimetric analysis. J Therm Anal Calorim 2010; doi: 10.1007/s10973-011-1342-y.

[23] Haykiri-Acma H, Turan AZ, Yaman S, Kucukbayrak S. Controlling the excess heat from oxy-combustion of coal by blending with biomass. Fuel Process Technol 2010;91:1569-75.

[24] Arias B, Pevida C, Fermoso J, Plaza MG, Rubiera F, Pis JJ. Influence of torrefaction on the grindability and reactivity of woody biomass. Fuel Process Technol 2008;89:169-75. 
[25] Álvarez L, Gharebaghi M, Pourkashanian M, Willians A, Riaza J, Pevida C, Pis JJ, Rubiera F. CFD modelling of oxy-coal combustion in an entrained flow reactor. Fuel Process Technol 2011;92:1489-97.

[26] Álvarez L, Riaza J, Gil MV, Pevida C, Pis JJ, Rubiera F. NO emissions in oxy-coal combustion with the addition of steam in an entrained flow reactor. Greenhouse Gas Sci Technol 2011;1:180-90.

[27] Lu GQ, Do DD. Comparison of structural models for high-ash char gasification. Carbon 1994;32:247-63.

[28] Ishida M, Wen CY. Comparison of zone-reaction model and unreacted-core shrinking model in solid-gas reactions - I Isothermal analysis. Chem Eng Sci 1971;26:1031-41.

[29] Szekely J, Evans JW. A structural model for gas-solid reactions with a moving boundary. Chem Eng Sci 1970;25:1091-107.

[30] Bhatia SK, Perlmutter DD. A random pore model for fluid-solid reactions: I. Isothermal, kinetic control. AIChE J 1980;26:379-86.

[31] Leroy V, Cancellieri D, Leoni E, Rossi JL. Kinetic study of forest fuels by TGA: Model-free kinetic approach for the prediction of phenomena. Thermochim Acta 2010;497:1-6.

[32] Miura K, Nakagawa H, Nakai S, Kajitani S. Analysis of gasification reaction of coke formed using a miniature tubing-bomb reactor and a pressurized drop tube furnace at high pressure and high temperature. Chem Eng Sci 2004;59:5261-8.

[33] Várhegyi G. Aims and methods in non-isothermal reaction kinetics. J Anal Appl Pyrolysis 2007;79:278-88.

[34] Aranda A, Murillo R, García T, Callén MS, Mastral AM. Steam activation of tyre pyrolytic carbon black: Kinetic study in a thermobalance. Chem Eng J 2007; 126:79-85.

[35] Gil MV, Riaza J, Álvarez L, Pevida C, Pis JJ, Rubiera F. Oxy-fuel combustion kinetics and morphology of coal chars obtained in $\mathrm{N}_{2}$ and $\mathrm{CO}_{2}$ atmospheres in an entrained flow reactor. Appl Energy 2012;91:67-74.

[36] Liu H. Combustion of coal chars in $\mathrm{O}_{2} / \mathrm{CO}_{2}$ and $\mathrm{O}_{2} / \mathrm{N}_{2}$ mixtures: a comparative study with non-isothermal thermogravimetric analyzer (TGA) tests. Energy Fuels 2009;23:4278-85.

[37] Rathnam RK, Elliott LK, Wall TF, Liu Y, Moghtaderi B. Differences in reactivity of pulverised coal in air $\left(\mathrm{O}_{2} / \mathrm{N}_{2}\right)$ and oxy-fuel $\left(\mathrm{O}_{2} / \mathrm{CO}_{2}\right)$ conditions. Fuel Process Technol 2009;90:797-802.

[38] Borrego AG, Garavaglia L, Kalkreuth WD. Characteristics of high heating rate biomass chars prepared under $\mathrm{N}_{2}$ and $\mathrm{CO}_{2}$ atmospheres. Int $\mathrm{J}$ Coal Geol 2009;77:409-15.

[39] Várhegyi G, Szabó P, Jakab E, Till F. Mathematical modeling of char reactivity in Ar- $\mathrm{O}_{2}$ and $\mathrm{CO}_{2}-\mathrm{O}_{2}$ mixtures. Energy Fuels 1996;10:1208-14. 


\section{Figure captions}

Fig. 1. Experimental conversion curves for AC-N2 (a), AC-CO2 (b), HVN-N2 (c), HVN-CO2 (d), DAB-N2 (e) and DAB-CO2 (f) coal chars during oxy-fuel combustion $\left(30 \% \mathrm{O}_{2}-70 \% \mathrm{CO}_{2}\right)$ and those calculated with three nth-order reaction models (VM, GM and RPM) using parameters determined from heating rates at 2, 3 and $5 \mathrm{~K} \mathrm{~min}^{-1}$.

Fig. 2. Experimental conversion curves for TPIN-N2 (a), TPIN-CO2 (b), AC+TPIN (c) and DAB+TPIN (d) samples during oxy-fuel combustion $\left(30 \% \mathrm{O}_{2}-70 \% \mathrm{CO}_{2}\right)$ and those calculated with three nth-order reaction models (VM, GM and RPM) using parameters determined from heating rates at 2, 3 and $5 \mathrm{~K} \mathrm{~min}^{-1}$.

Fig. 3. Comparison between the apparent oxy-fuel combustion reaction rates for HVN$\mathrm{N} 2$ and HVN-CO2 obtained from TPR data (at heating rates of 2, 3 and $5 \mathrm{~K} \mathrm{~min}^{-1}$ ) and data obtained from isothermal experiments [35].

Fig. 4. Comparison between the experimental and theoretical (according to the additive rule from those of the individual components) reaction rate curves for the AC+TPIN (a) and DAB+TPIN (b) blends during non-isothermal (2, 3 and $\left.5 \mathrm{~K} \mathrm{~min}^{-1}\right)$ oxy-fuel combustion. 
Table 1. Proximate and ultimate analyses and high heating value of the samples

\begin{tabular}{lccccccc}
\hline Sample & AC & HVN & DAB & M6N & NZ & PIN & TPIN \\
\hline Origin & Spain & Spain & China & Mexico & $\begin{array}{c}\text { New } \\
\text { Zealand }\end{array}$ & Spain & Spain \\
\hline Rank & an & sa & hvb & hvb & hvb & & \\
\hline Moisture (wt.\%) & 2.3 & 1.1 & 2.9 & 1.8 & 11.5 & 6.8 & -- \\
Ash (wt.\%, db) & 14.2 & 10.7 & 10.9 & 30.2 & 2.9 & 3.8 & 4.2 \\
V.M. (wt.\%, db) & 3.6 & 9.2 & 28.8 & 30.6 & 47.9 & 79.8 & 75.5 \\
F.C. (wt.\%, db) & 82.2 & 80.1 & 60.3 & 39.2 & 49.2 & 16.4 & 20.3 \\
\hline Ultimate Analysis (wt.\%, daf) & & & & & & \\
C & 94.7 & 91.7 & 81.9 & 76.7 & 67.5 & 45.9 & 51.2 \\
H & 1.6 & 3.5 & 5.0 & 6.2 & 5.3 & 6.1 & 5.7 \\
N & 1.0 & 1.9 & 1.1 & 1.6 & 1.0 & 0.7 & 0.9 \\
S & 0.7 & 1.6 & 1.2 & 1.2 & 0.2 & 0.0 & 0.0 \\
$\mathrm{O}^{\text {b }}$ & 2.0 & 1.3 & 10.8 & 14.3 & 26.0 & 47.3 & 42.2 \\
\hline HHV (MJ/kg, db) & 29.2 & 31.8 & 28.8 & 23.1 & 27.9 & 18.9 & 20.2 \\
\hline
\end{tabular}

an: anthracite; sa: semi-anthracite; hvb: high-volatile bituminous coal.

$\mathrm{db}$ : dry basis; daf: dry and ash free bases.

${ }^{a}$ The proximate analysis was conducted in a LECO TGA-601, and the ultimate analysis in a LECO CHNS-932.

${ }^{\mathrm{b}}$ Calculated by difference. 
Table 2. Kinetic parameters of the chars during oxy-fuel combustion $\left(30 \% \mathrm{O}_{2}-70 \% \mathrm{CO}_{2}\right)$ determined with the TPR technique at three heating rates for VM, GM and RPM models

\begin{tabular}{|c|c|c|c|c|c|c|c|c|c|}
\hline \multirow[t]{2}{*}{ Char } & \multicolumn{3}{|c|}{ Volumetric model (VM) } & \multicolumn{2}{|c|}{ Grain model (GM) } & \multicolumn{4}{|c|}{ Random pore model (RPM) } \\
\hline & $\begin{array}{c}E \\
\left(\mathrm{~kJ} \mathrm{~mol}^{-1}\right) \\
\end{array}$ & $k_{0}\left(\mathrm{~s}^{-1}\right)$ & $R^{2}$ & $\begin{array}{c}E \\
\left(\mathrm{~kJ} \mathrm{~mol}^{-1}\right)\end{array}$ & $k_{0}\left(\mathrm{~s}^{-1}\right)$ & $\begin{array}{c}E \\
\left(\mathrm{~kJ} \mathrm{~mol}^{-1}\right)\end{array}$ & $k_{0}\left(\mathrm{~s}^{-1}\right)$ & $\psi$ & $R^{2}$ \\
\hline $\mathrm{AC}-\mathrm{N} 2$ & 260 & $4.45 \mathrm{E}+13$ & $0.977 *$ & 194 & $1.83 \mathrm{E}+090.970 *$ & 137 & $1.43 \mathrm{E}+04$ & 2955 & $0.999 *$ \\
\hline $\mathrm{AC}-\mathrm{CO} 2$ & 234 & $7.96 \mathrm{E}+11$ & $0.987 *$ & 169 & $3.54 \mathrm{E}+070.980 *$ & 140 & $5.88 \mathrm{E}+04$ & 490 & $0.999 *$ \\
\hline HVN-N2 & 184 & $1.08 \mathrm{E}+09$ & $0.995^{*}$ & 149 & $4.13 \mathrm{E}+060.994^{*}$ & 128 & $6.88 \mathrm{E}+04$ & 19.1 & $0.998^{*}$ \\
\hline $\mathrm{HVN}-\mathrm{CO} 2$ & 190 & $2.75 \mathrm{E}+09$ & $0.996^{*}$ & 157 & $1.25 \mathrm{E}+070.995^{*}$ & 116 & $7.72 \mathrm{E}+03$ & 37.1 & $0.998^{*}$ \\
\hline DAB-N2 & 146 & $8.10 \mathrm{E}+06$ & $0.998^{*}$ & 113 & $2.95 \mathrm{E}+040.992 *$ & 152 & $2.03 \mathrm{E}+07$ & -0.2 & $0.999 *$ \\
\hline DAB-CO2 & 152 & $1.82 \mathrm{E}+07$ & $0.998^{*}$ & 117 & $5.27 \mathrm{E}+040.98$ & 160 & $7.25 \mathrm{E}$ & -0.2 & $0.999 *$ \\
\hline M6N-N2 & 171 & $1.47 \mathrm{E}+09$ & $0.995^{*}$ & 106 & $1.83 \mathrm{E}+040.970 *$ & 175 & $2.77 \mathrm{E}+09$ & -0.2 & $0.996^{*}$ \\
\hline M6N-CO2 & 166 & $5.73 \mathrm{E}+08$ & $0.996^{*}$ & 110 & $3.48 \mathrm{E}+040.973 *$ & 171 & $1.57 \mathrm{E}+09$ & -0.2 & $0.997 *$ \\
\hline NZ-N2 & 131 & $1.13 \mathrm{E}+07$ & $0.998 *$ & 76 & $2.81 \mathrm{E}+020.954^{*}$ & 134 & $2.17 \mathrm{E}+07$ & -0.2 & $0.999 *$ \\
\hline $\mathrm{NZ}-\mathrm{CO} 2$ & 141 & $1.37 \mathrm{E}+08$ & $0.996^{*}$ & 63 & $2.78 \mathrm{E}+010.908 *$ & 142 & $1.60 \mathrm{E}+08$ & -0.1 & $0.996^{*}$ \\
\hline TPIN-N2 & 118 & $9.60 \mathrm{E}+05$ & $0.998 *$ & 96 & $1.31 \mathrm{E}+040.996^{*}$ & 112 & $2.68 \mathrm{E}+05$ & 0.4 & 0.998 \\
\hline TPIN-CO2 & 129 & $6.29 \mathrm{E}+06$ & $0.996^{*}$ & 102 & $3.72 \mathrm{E}+040.992 *$ & 128 & $5.42 \mathrm{E}+06$ & 0.03 & 0.996 \\
\hline DAB+TPIN & 136 & $1.42 \mathrm{E}+06$ & $0.999 *$ & 102 & $5.03 \mathrm{E}+030.991 *$ & 141 & $3.73 \mathrm{E}+06$ & -0.2 & $0.999 *$ \\
\hline
\end{tabular}

*Statistically significant 
Table 3. Deviation (\%) between the experimental and calculated conversion $(1-X)$ data

\begin{tabular}{lccc}
\hline Char & \multicolumn{3}{c}{ DEV 1- $X(\%)$} \\
\cline { 2 - 4 } & VM & GM & RPM \\
\hline AC-N2 & 6.39 & 7.94 & 1.24 \\
AC-CO2 & 4.36 & 5.40 & 1.08 \\
HVN-N2 & 2.80 & 3.07 & 1.57 \\
HVN-CO2 & 2.30 & 2.72 & 1.41 \\
DAB-N2 & 1.53 & 3.45 & --- \\
DAB-CO2 & 1.63 & 4.09 & --- \\
M6N-N2 & 2.89 & 6.73 & --- \\
M6N-CO2 & 2.52 & 6.11 & --- \\
NZ-N2 & 1.63 & 8.01 & --- \\
NZ-CO2 & 2.67 & 11.84 & --- \\
TPIN-N2 & 1.82 & 2.16 & --- \\
TPIN-CO2 & 2.30 & 3.18 & --- \\
DAB+TPIN & 1.08 & 3.50 & --- \\
\hline
\end{tabular}


Table 4. Comparison of the activation energy values obtained in the present work and in previous oxy-fuel combustion studies.

\begin{tabular}{|c|c|c|c|c|}
\hline Sample & Atmosphere & $E\left(\mathrm{~kJ} \mathrm{~mol}^{-1}\right)$ & Model & Reference \\
\hline Coal chars & $30 \% \mathrm{O}_{2}-70 \% \mathrm{CO}_{2}$ & $116-171 \mathrm{~kJ} \mathrm{~mol}^{-1}$ & $\begin{array}{l}\text { nth-order gas-solid } \\
\text { models }\end{array}$ & Present study \\
\hline Coal chars & $30 \% \mathrm{O}_{2}-70 \% \mathrm{CO}_{2}$ & $117-127 \mathrm{~kJ} \mathrm{~mol}^{-1}$ & $\begin{array}{l}\text { nth-order gas-solid } \\
\text { models }\end{array}$ & Gil et al. (2012) [35] \\
\hline $\begin{array}{l}\text { Pulverized } \\
\text { coals }\end{array}$ & $20 \% \mathrm{O}_{2}-80 \% \mathrm{CO}_{2}$ & $109-248 \mathrm{~kJ} \mathrm{~mol}^{-1}$ & Coats-Redfern method & Niu et al. (2009) [5] \\
\hline Coal chars & $10 \% \mathrm{O}_{2}-90 \% \mathrm{CO}_{2}$ & $115-147 \mathrm{~kJ} \mathrm{~mol}^{-1}$ & $\begin{array}{l}\text { Isoconversional model- } \\
\text { free methods }\end{array}$ & Liu (2009) [36] \\
\hline Biomass chars & $30 \% \mathrm{O}_{2}-70 \% \mathrm{CO}_{2}$ & $118-129 \mathrm{~kJ} \mathrm{~mol}^{-1}$ & $\begin{array}{l}\text { nth-order gas-solid } \\
\text { models }\end{array}$ & Present study \\
\hline $\begin{array}{l}\text { Coal/biomass } \\
\text { char blend }\end{array}$ & $30 \% \mathrm{O}_{2}-70 \% \mathrm{CO}_{2}$ & $136 \mathrm{~kJ} \mathrm{~mol}^{-1}$ & $\begin{array}{l}\text { nth-order gas-solid } \\
\text { models }\end{array}$ & Present study \\
\hline
\end{tabular}



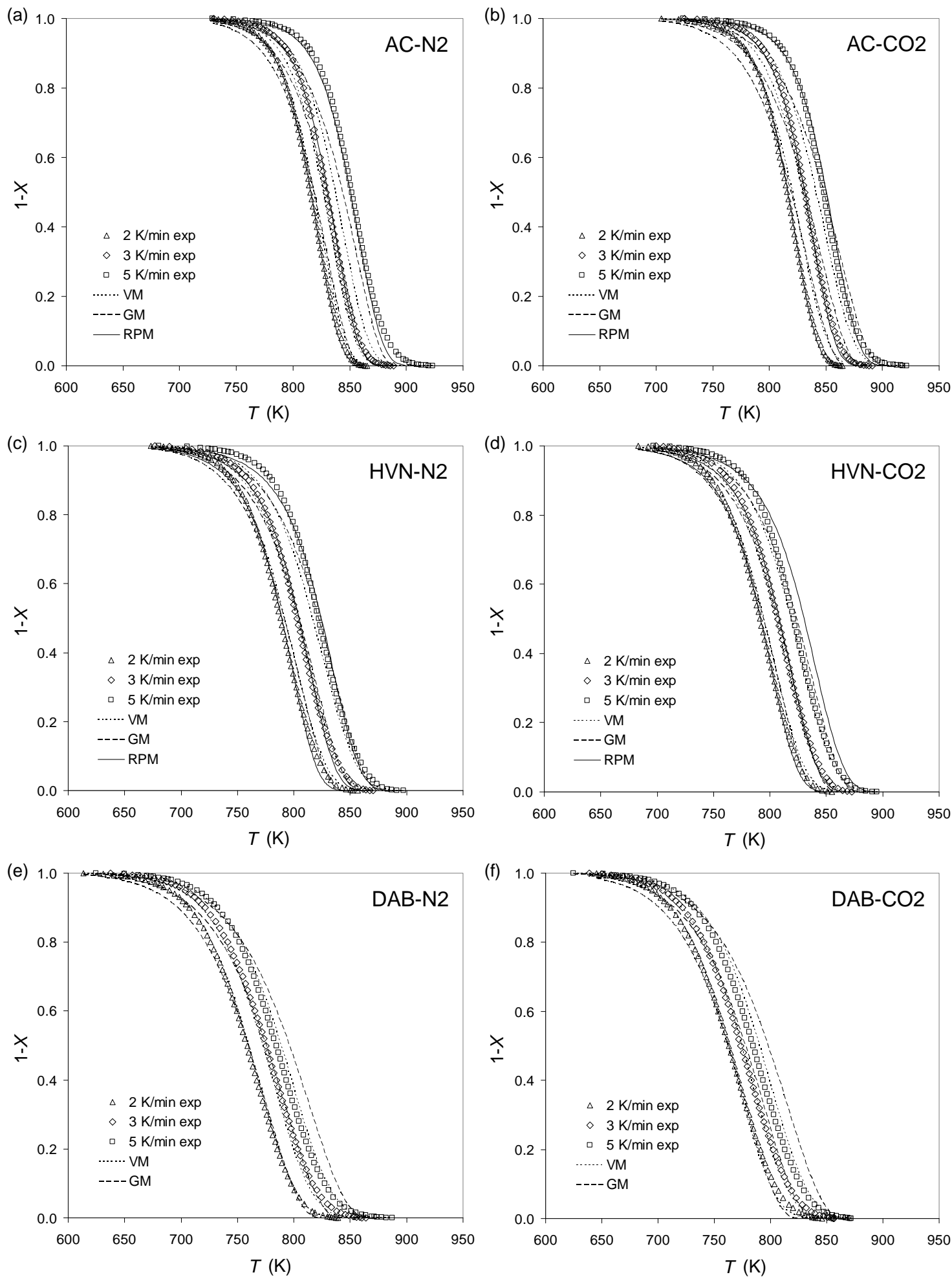

Fig. 1. Experimental conversion curves for AC-N2 (a), AC-CO2 (b), HVN-N2 (c), HVN-CO2 (d), DAB-N2 (e) and DAB-CO2 (f) coal chars during oxy-fuel combustion $\left(30 \% \mathrm{O}_{2}-70 \% \mathrm{CO}_{2}\right)$ and those calculated with three nth-order reaction models (VM, GM and RPM) using parameters determined from heating rates at 2, 3 and $5 \mathrm{~K} \mathrm{~min}^{-1}$. 

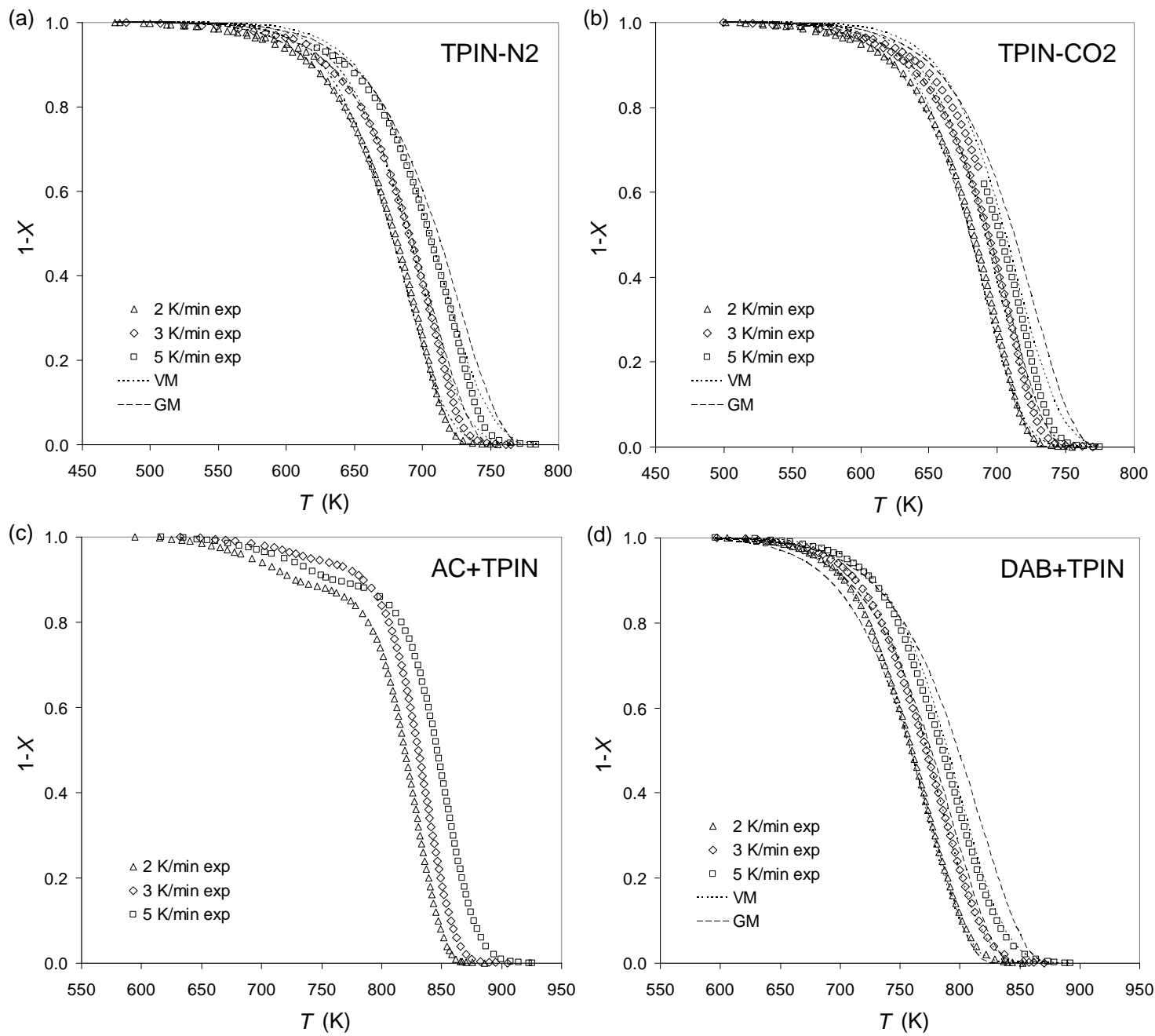

Fig. 2. Experimental conversion curves for TPIN-N2 (a), TPIN-CO2 (b), AC+TPIN (c) and DAB+TPIN (d) samples during oxy-fuel combustion $\left(30 \% \mathrm{O}_{2}-70 \% \mathrm{CO}_{2}\right)$ and those calculated with three nth-order reaction models (VM, GM and RPM) using parameters determined from heating rates at 2, 3 and $5 \mathrm{~K} \mathrm{~min}^{-1}$. 


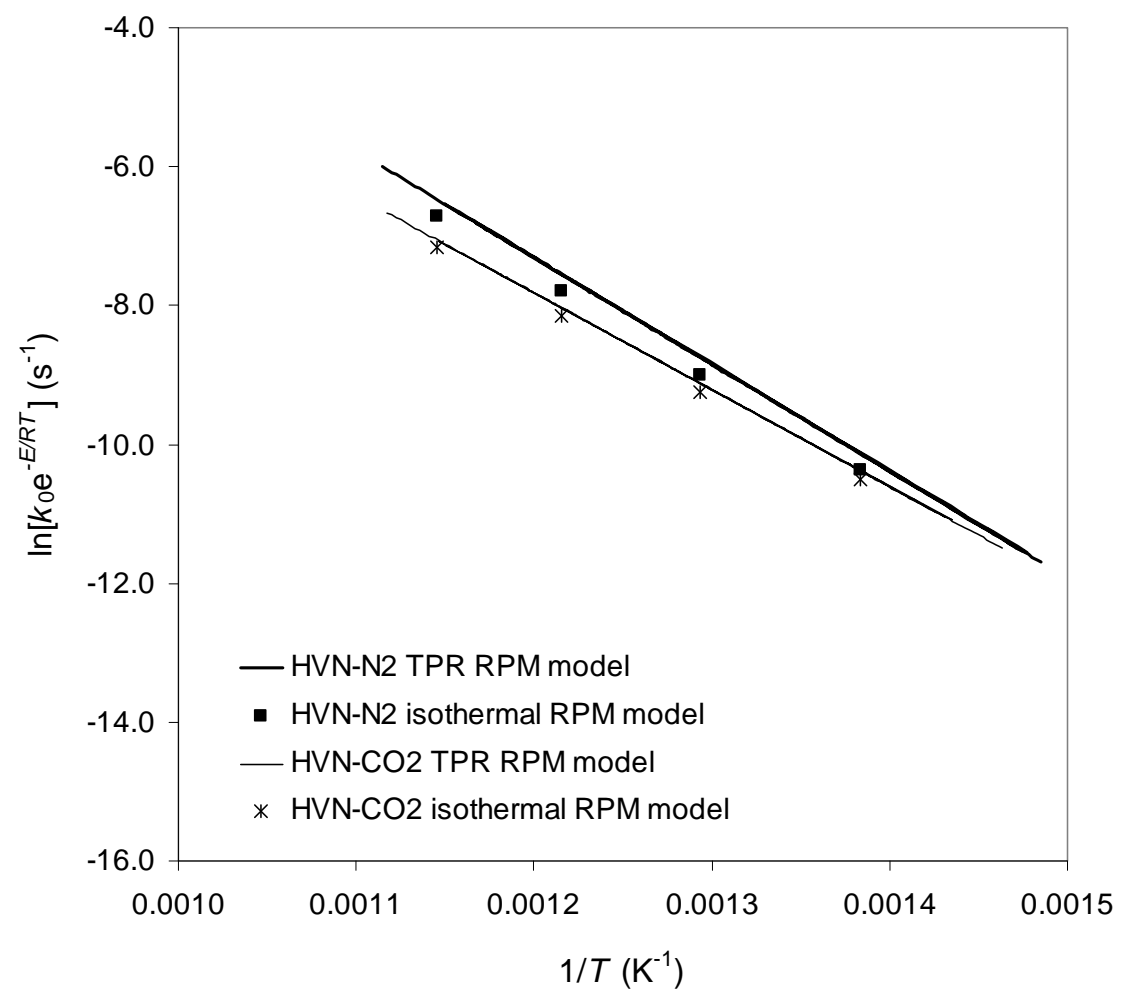

Fig. 3. Comparison between the apparent oxy-fuel combustion reaction rates for HVN$\mathrm{N} 2$ and HVN-CO2 obtained from TPR data (at heating rates of 2, 3 and $5 \mathrm{~K} \mathrm{~min}^{-1}$ ) and data obtained from isothermal experiments [34]. 

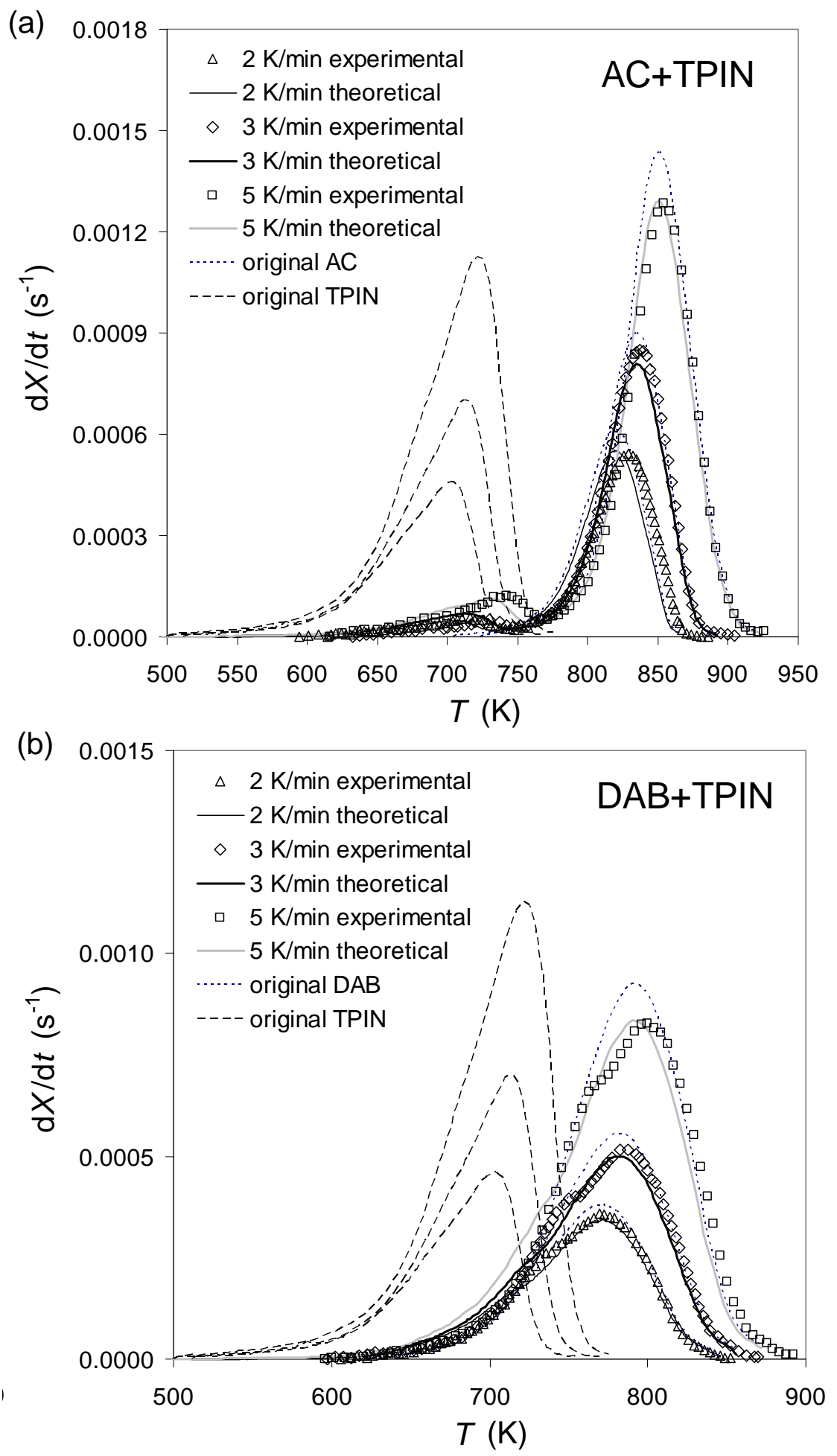

Fig. 4. Comparison between the experimental and theoretical (according to the additive rule from those of the individual components) reaction rate curves for the AC+TPIN (a) and DAB+TPIN (b) blends during non-isothermal $\left(2,3\right.$ and $\left.5 \mathrm{~K} \mathrm{~min}^{-1}\right)$ oxy-fuel combustion. 